\title{
HOMER: a human organ-specific molecular electronic repository
}

\author{
Fan Zhang ${ }^{1,3}$, Jake $Y$ Chen $^{1,2,3^{*}}$ \\ From Eighth Annual MCBIOS Conference. Computational Biology and Bioinformatics for a New Decade \\ College Station, TX, USA. 1-2 April 2011
}

\begin{abstract}
Background: Each organ has a specific function in the body. "Organ-specificity" refers to differential expressions of the same gene across different organs. An organ-specific gene/protein is defined as a gene/protein whose expression is significantly elevated in a specific human organ. An "organ-specific marker" is defined as an organspecific gene/protein that is also implicated in human diseases related to the organ. Previous studies have shown that identifying specificity for the organ in which a gene or protein is significantly differentially expressed, can lead to discovery of its function. Most currently available resources for organ-specific genes/proteins either allow users to access tissue-specific expression over a limited range of organs, or do not contain disease information such as disease-organ relationship and disease-gene relationship.

Results: We designed an integrated Human Organ-specific Molecular Electronic Repository (HOMER, http://bio. informatics.iupui.edu/homer), defining human organ-specific genes/proteins, baséd on five criteria: 1) comprehensive organ coverage; 2) gene/protein to disease association; 3) disease-organ association; 4) quantification of organ-specificity; and 5) cross-linking of multiple available data sources.

HOMER is a comprehensive database covering about 22,598 proteins, 52 organs, and 4,290 diseases integrated and filtered from organ-specific proteins/genes and disease databases like dbEST, TiSGeD, HPA, CTD, and Disease Ontology. The database has a Web-based user interface that allows users to find organ-specific genes/proteins by gene, protein, organ or disease, to explore the histogram of an organ-specific gene/protein, and to identify disease-related organ-specific genes by browsing the disease data online.

Moreover, the quality of the database was validated with comparison to other known databases and two case studies: 1) an association analysis of organ-specific genes with disease and 2) a gene set enrichment analysis of organ-specific gene expression data.

Conclusions: HOMER is a new resource for analyzing, identifying, and characterizing organ-specific molecules in association with disease-organ and disease-gene relationships. The statistical method we developed for organspecific gene identification can be applied to other organism. The current HOMER database can successfully answer a variety of questions related to organ specificity in human diseases and can help researchers in discovering and characterizing organ-specific genes/proteins with disease relevance.
\end{abstract}

\section{Background}

Organ-specific patterns of gene expression can give important clues about gene function and organ characteristics. High-throughput sequencing methods offer the opportunity to examine patterns of gene expression on

\footnotetext{
* Correspondence: jakechen@iupui.edu

${ }^{1}$ School of Informatics, Indiana University, Indianapolis, IN 46202, USA

Full list of author information is available at the end of the article
}

a genome scale and generate an abundance of data describing the expression of gene transcripts within various human organs and disease states to facilitate transcriptomic studies [1]. Organ-specificity expression profiling has been widely used for identifying potentially therapeutic genes related to specific organs [2] and understanding the characteristics of cells and tissues in an organ in terms of their differential expression of

\section{() Biomed Central}


genes [3]. For example, Andrew Su etc. have designed custom arrays that interrogate the expression of the vast majority of protein-encoding human and mouse genes, and have used them to profile a panel of 79 human and 61 mouse tissues or organs [4]. Previous researches have identified organ-specific genes that are specifically expressed in the testis [2], the heart [5], the prostate [6], the brain [7], and the bladder [8] etc. For example, Kouame etc. identified the genes uniquely detected in each of the 15 tissues or organs such as testis, prostate, ovary, mammary gland, uterus, vagina, skin, liver, adipose tissue, lung, bone, skeletal muscle, cerebral cortex, hypothalamus, and pituitary gland. Their study shows that 61 organ-specific transcripts in the testis are statistically different from the other organs and that some transcripts such as dipeptidase 3 , ankyrin repeat domain 5 , and ubiquitin-conjugating enzyme E2N are exclusively found in the testis [2]. They have also identified some prostate specific genes such as microseminoprotein (beta-MSP), seminal vesicle protein secretion 2 , seminal vesicle antigen (SVA) and mucin 10 (MUC10) which are involved in protein secretion, cell signaling and spermatogenesis.

For "organ-specificity of gene expression", we refer to differential expressions of the same gene across different organs. In particular, we define an "organ-specific gene/ protein" as a gene/protein whose expression is significantly elevated in a specific human organ. However, the expression level of the organ-specific gene/protein may vary in an organ under certain circumstances, which makes the organ-specificity questionable. Therefore, we need to quantify organ specificity based on organ context. Highly expressed genes/proteins with high quantitative organ specificity levels are also implicated in human diseases related to the organ. In other words, they may be used as an indicator of the normal/abnormal physiological states of the organ. We refer to them as "organ-specific markers".

The organ-specific gene/protein can be used as an indicator to measure the function of a tissue in a respective organ. The organ-specific gene/protein can indicate important clues about gene function [4] and also monitor organ integrity both during preclinical toxicological assessment and clinical safety testing of investigational drugs. Additionally, it may provide valuable information for decision making during toxicological assessment and may be used for sensitive and specific target organ monitoring during clinical trials [9].

There are a number of databases today that include information on tissue specific expression of genes/proteins, for example, TiGER [10], TiSGeD [11], and HPA [12]. These resources have several limitations. First, they all uses organ name to present tissue. For example, brain is considered as a tissue and not an organ. Tissue is a group of cells that perform specific functions. An organ is a group of tissues that perform a specific function or group of functions. Also it is common to know what organ system is involved in a disease and diseases are mostly categorized by human organ system. Therefore, we need to map tissues to organs and use organ name instead of tissue name for calculating organ-specificity and building the disease-organ association which is more accurate than disease-tissue relationship. Second, they have a low coverage of organs and genes. For example, TiGER [10] covers only 30 organs. It includes expression values for genes and has Gene ID's, but no protein information is presented. 1,494 out of 6,698 UniGene IDs have been retired since its last update in 2008. In TiSGed [11], 18 organs are covered. It defines tissues by organ name in a tree fashion, but all tissues in an organ are not covered and protein information is not presented. HPA (Human Protein Atlas) [12] provides a range of 74 tissue-specific proteins which cover 24 organs based on the protein levels in 65 normal cell types. Although HPA's normal tissue data contains 11261 Ensembl genes, their expression values are based on the annotated expression levels: "Negative", "Moderate", "Strong", "Weak", "Medium", "High", "None", and "Low." No real number value for expression is given, which makes digitizing the expression values very challenging and calculating organ specificity questionable. For example, How to accurately digitally distinguish between the "Strong" and "High", the "Weak" and "Low", and the "Moderate" and "Medium?". Last, they don't contain disease information such as disease-organ relationship and disease-gene relationship.

For studies focusing on organ-specificity with relation to diseases, it is desirable that the database should house data from a range of organs, have quantitative organ specificity and, more importantly, disease information. Therefore, as described in this paper, we designed an integrated database defining human organspecific molecule (gene/protein). In our organ-specific molecule design we considered five criteria: 1) comprehensive organ coverage; 2) gene/protein to disease association; 3) disease-organ association; 4) quantification of organ-specificity; and 5) cross-linking of multiple available data sources.

The Human Organ-specific Molecular Electronic Repository (HOMER), located at http://bio.informatics. iupui.edu/homer/ is a comprehensive database covering about 22,598 proteins, 52 organs, and 4,290 diseases integrated from databases including dbEST [13], TiSGeD [11], HPA [12], CTD [14], and Disease Ontology [15]. It is the first comprehensive database that can be used to analyze, identify, and characterize organ-specific molecules in association with disease-organ and disease-protein relationships. The gene/protein to 
disease and disease-organ associations allow future identification of organ-specific markers. The comprehensive 52 organs in 13 human organ systems and the ability to choose quantitative variables (p-value, z-score, \#EST, and Adjusted \#EST) provide us with power statistics and computation to accurately calculate organ specificity. And the cross-linking of multiple data sources enables subsequent validation.

The database has a Web-based user interface that allows users to query organ-specific genes/proteins by gene, protein, organ, or disease, browse organ-specific genes/proteins by human organ system and disease ontology, explore a histogram of each organ-specific gene/protein, and identify disease-related genes or disease-related organs.

Moreover, two case studies were performed to demonstrate and validate that the repository can help researchers discover and characterize organ-specific protein molecules implicated in human diseases related to the organ: 1) an association analysis of organ-specific genes with disease and 2) a gene set enrichment analysis of organ-specific gene expression data.

\section{Results}

\section{Database content statistics}

By integrating organ-specific protein/genes and disease databases including dbEST [13], TiSGeD [11], HPA [12], CTD [14], and Disease Ontology [15], we have developed HOMER, the Human Organ-specific Molecular Electronic Repository. As of the current release (June 2011), HOMER contains 22,598 proteins (IPI IDs), 5,703 genes (gene IDs), 52 organs, and 4,290 diseases (MeSH IDs) of which 4492 are disease-related organ-specific genes (gene IDs) and 2000 are identified as organ-specific markers (gene IDs) (Table 1). A comparison of organ-specific genes/proteins in HOMER against several common human tissue/organspecific data sources is shown in Table 2.

\section{General online features}

In Figure 1, we show the user interfaces of the webbased online version of HOMER. It supports both

\section{Table 1 Current statistics of database}

\begin{tabular}{ll}
\hline Total Number & Count \\
\hline Organs & 52 \\
Genes & 111367 UniGene IDs \\
Proteins & 76755 IPI IDs \\
Organ-specific Genes & 5703 GenelDs, 6999 \\
& UniGenelDs \\
Disease-related and Organ-specific & 4492 \\
Genes & \\
Organ-specific Markers & 2000 \\
Diseases & 4290 \\
\hline
\end{tabular}

standard and customized search options that allow users to specify a list of genes/proteins or keywords as the query input. In the Advanced Search interface, users can drill down in very specific ways, including referencing a list of genes/proteins, searching within p-value, z-score, number of EST, and adjusted number of EST ranges, and looking for organ-specific genes/proteins related to specific organs, disease MeSH IDs, or dbEST library IDs. One of the more interesting features of HOMER is the ability to browse for organ-specific genes/proteins by human organ system and disease ontology.

In response to these queries, HOMER can retrieve a list of related organ-specific genes in a highly flexible table, with which users can further explore details about organ-specific genes/proteins. For example, users can browse gene symbol, p-value and z-score for each gene/ protein, explore the organ-specific expressions of the HMID by clicking on the histogram icon in the table, and look through the gene-related diseases and diseaserelated organs by clicking on the disease relevance icon in the last column. In the histogram, users can browse the dbEST libraries and reference sources which contain the ESTs related to the gene/protein. The organ-specific genes/proteins are freely available for downloading in tab-delimited format on the download page. User queried organ-specific gene/protein data stored in HOMER can also be freely downloaded as tab-delimited text files using links below each organ-specific gene/protein table.

\section{Overlap of OSGs among organs}

We used a heatmap to show the overlap of OSGs among the 52 organs (Figure 2). The 3 organs which show more than 300 organ-specific genes are testis (773); blood vessel (549); and brain (369), while gallbladder (11), spinal cord (6), peritoneum (2), and ureter (2) have the least number of organ-specific genes in our study.

When we tightened the criteria from $R Z \geq 4$ to $R Z \geq$ 5 , we found that there is no overlapping among the 52 organs. We also found that the distribution of organ specificity of genes between the 52 organs marginally changes with the increase in relative $\mathrm{z}$-score. This suggests that those top organs with more organ-specific genes are much more organ-specific than the other organs.

Figure 2 shows that the liver and the spleen have the largest number of OSGs in common: 16. The other large overlapping of OSGs between organs are heart and muscle (7), bladder and salivary gland (4), ear and leiomios (3, leiomyoma), esophagus and mouth (3), and lymph and lymph node (3).

\section{Validation by HPA}

Selecting the top three genes from each organ, we found 154 organ-specific genes in UniGeneIDs (152 in 
Table 2 A comparison of human organ-specific genes/proteins in HOMER against several common human tissue/ organ-specific data sources

\begin{tabular}{|c|c|c|c|c|c|}
\hline & TissueDistributionDBs[3] & TiGER[10] & TiSGeD[11] & HPA[12] & HOMER \\
\hline Organ coverage & 40 & 30 & 18 & 24 & 52 \\
\hline Gene coverage & $1359^{*}$ & $4283^{* *}$ & $957^{* * *}$ & 74 & 5703 \\
\hline Last Updated & 2010 & March 2008 & July 2010 & Jan 2011 & June 2011 \\
\hline Criteria for organ-specific genes & TissueSpecificitylndex & $\begin{array}{l}p \text {-value }<1 \text { e-3.5 } \\
E E>5\end{array}$ & SPM & Exclusively detected in a single cell & $\begin{array}{l}\text { p-value } \leq 1 \mathrm{e}-5 \\
R Z \geq 4 \\
A E \geq 10 \\
R E \geq 4\end{array}$ \\
\hline Expression Value & Relative expression & Yes & No & No & Relative Expression \\
\hline Plasma Detectability & No & No & No & No & Yes \\
\hline Disease Association & No & No & No & No & Yes \\
\hline
\end{tabular}

*1359 gene IDs were filtered out from 54, 576 human UniGene IDs with TissueSpecificitylndex = 1. We used TissueSpecificitylndex = 1 as the website didn't recommend any criteria for us to derive organ-specific genes.

** 1494 of 6698 UniGene IDs were retired.

*** 957 gene IDs were filtered out from 2423 gene IDs with SPM $\geq 0.9$. We used SPM $\geq 0.9$ as the website didn't recommend any criteria for us to derive organspecific genes.

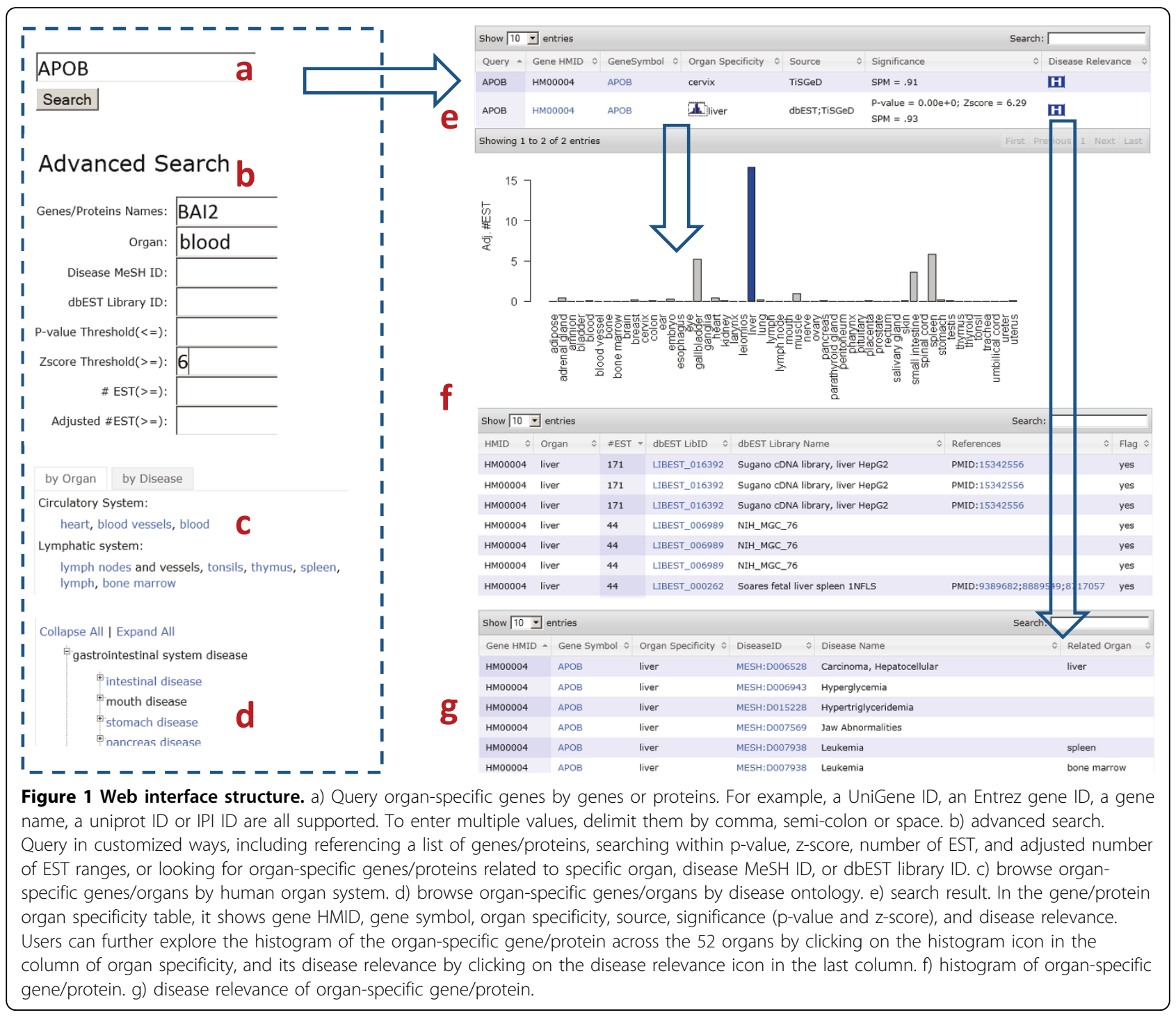




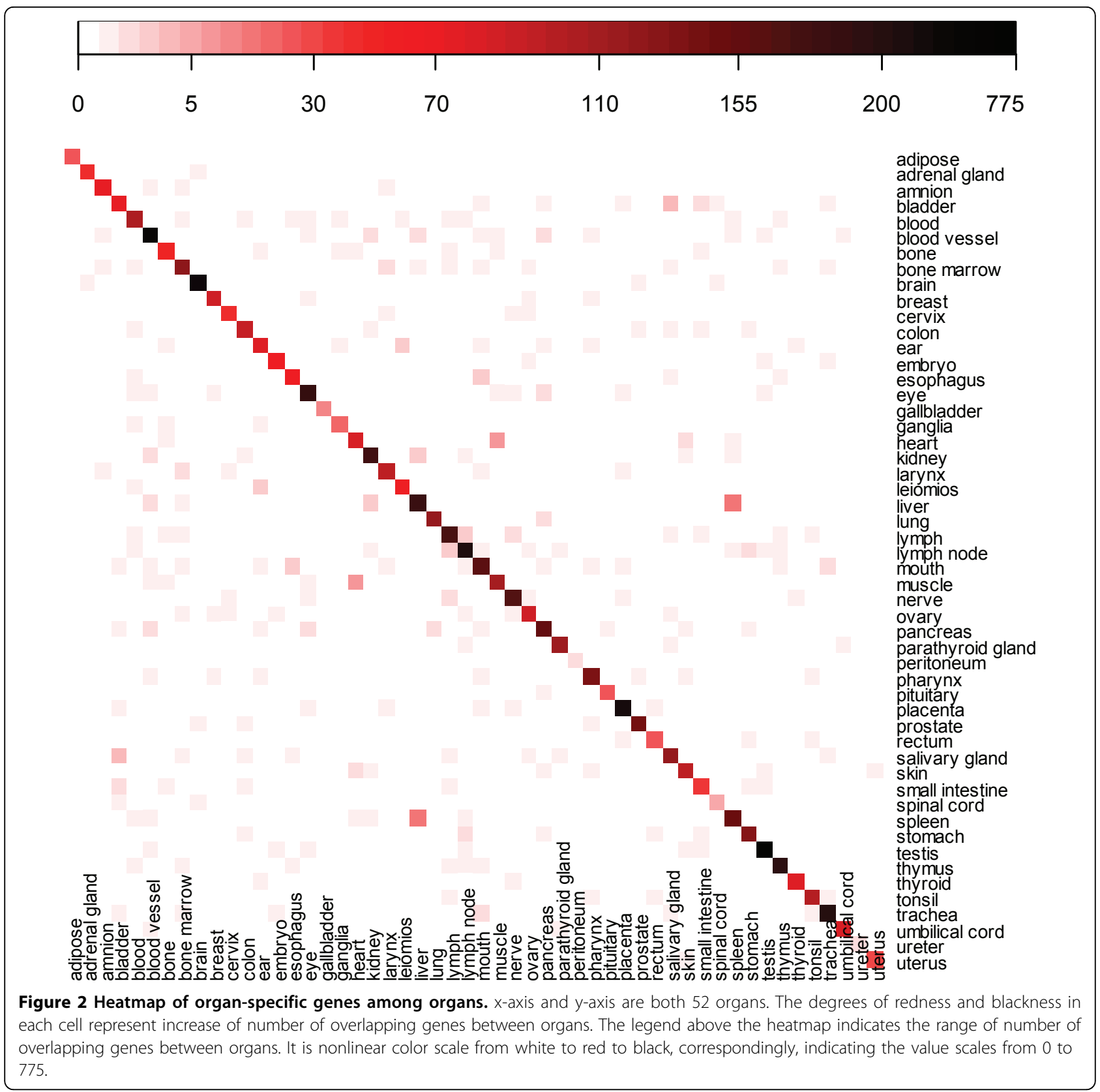

gene IDs; peritoneum and ureter only have two organspecific genes, 73 match with HPA data, Additional File 1). Based on expert experience, we digitalized the annotated protein expression in HPA. On a scale of 0 to 9, 'None' 0, 'Negative' is 1 , 'Low' 2, 'Weak' 3, 'Medium' 5, 'Moderate' 6, 'High' 7, and 'Strong' 9. After scoring the annotated protein expression, we used the similar statistics method for the dbEST data to calculate the $\mathrm{p}$-value and $\mathrm{z}$-score for HPA and found 25 (34\%) out of the overlapping 73 organ-specific genes in HOMER are specific to the same organ in HPA data (Additional File 1).
Pathway analysis, gene ontology categorization, and drug target analysis of organ-specific genes/proteins

The pathway-gene association matrix for the 154 organspecific genes is shown in the Additional File 2. The top two pathways are "Neuroactive ligand-receptor interaction" and "Ribosome." 15 disease/cancer-related pathways are included in the Additional File 2, which are "Pathways in cancer," "Jak-STAT signaling pathway," "Autoimmune thyroid disease," "PPAR signaling pathway," "Chemokine signaling pathway," "p53 signaling pathway," "Type I diabetes mellitus," "Alzheimer's disease," "Amyotrophic lateral sclerosis (ALS)," 
"Huntington's disease," "Vibrio cholerae infection," "Epithelial cell signaling in Helicobacter pylori infection," "Small cell lung cancer," "Allograft rejection," and "Graft-versus-host disease."

Figure 3 quantifies the significance of the biological process component of the gene ontology. The top 3 biological processes for the 154 organ-specific genes are "defense response," "immune response," and "homeostatic process."

In the Additional File 3, we list all drugs with which those 154 organ-specific genes interact as drug targets. Interestingly, we found some organ-specific drug targets are involved in a particular metabolic or signaling pathway that is specific to the organs as key molecules. For example, the two brain-specific biomarkers SV2A and GRM3 are used as drug targets of Levetiracetam, and Nicotine and Acamprosate, respectively, which is consistent with previous findings. Pediatr etc. studied 23 patients with cancer and seizures treated with Levetiracetam, and they observed that over $95 \%$ of patients had fewer seizures, with $65.2 \%$ becoming seizure free; only one patient experienced an adverse reaction. They concluded that Levetiracetam is effective and well tolerated in children with brain tumors and other cancers, who are often on multiple enzyme-inducing drugs [16].

One study shows that Nicotine can help improve some of the learning and memory problems associated with hypothyroidism. Such studies suggest that nicotine - or drugs that mimic nicotine - may one day prove beneficial in the treatment of neurological disorders [17]. Another new study has found that one of nicotine's metabolites, cotinine, may improve memory and protect brain cells from diseases such as Alzheimer's and Parkinson's [18].

Acamprosate, also known by the brand name Campral, is a drug used for treating alcohol dependence. Acamprosate is thought to stabilize the chemical balance in the brain that would otherwise be disrupted by alcoholism, possibly by blocking glutaminergic Nmethyl-D-aspartate receptors, while gamma-aminobutyric acid type A receptors are activated [19].

\section{Case studies}

It has been reported that organ-specific genes are often implicated in diseases related to specific organs. However, it remains largely unknown whether there is a correlation between the organ specificity of a gene/protein and the diseases associated with the organ. We show two case studies of increasing complexity and biological significance to achieve three goals: 1) to demonstrate that the database can help researchers discover and characterize organ-specific genes/proteins from experimental data, 2) to test the hypothesis that there is correlation between the organ specificity of a gene/protein and the associated diseases, and 3) thereby to validate the usefulness of our database.

\section{Case study 1: website features}

The liver is the human body's one of most important organs, functioning as a living filter to clean the system of toxins, metabolize proteins, control hormonal balance, and produce immune-boosting factors. In this case
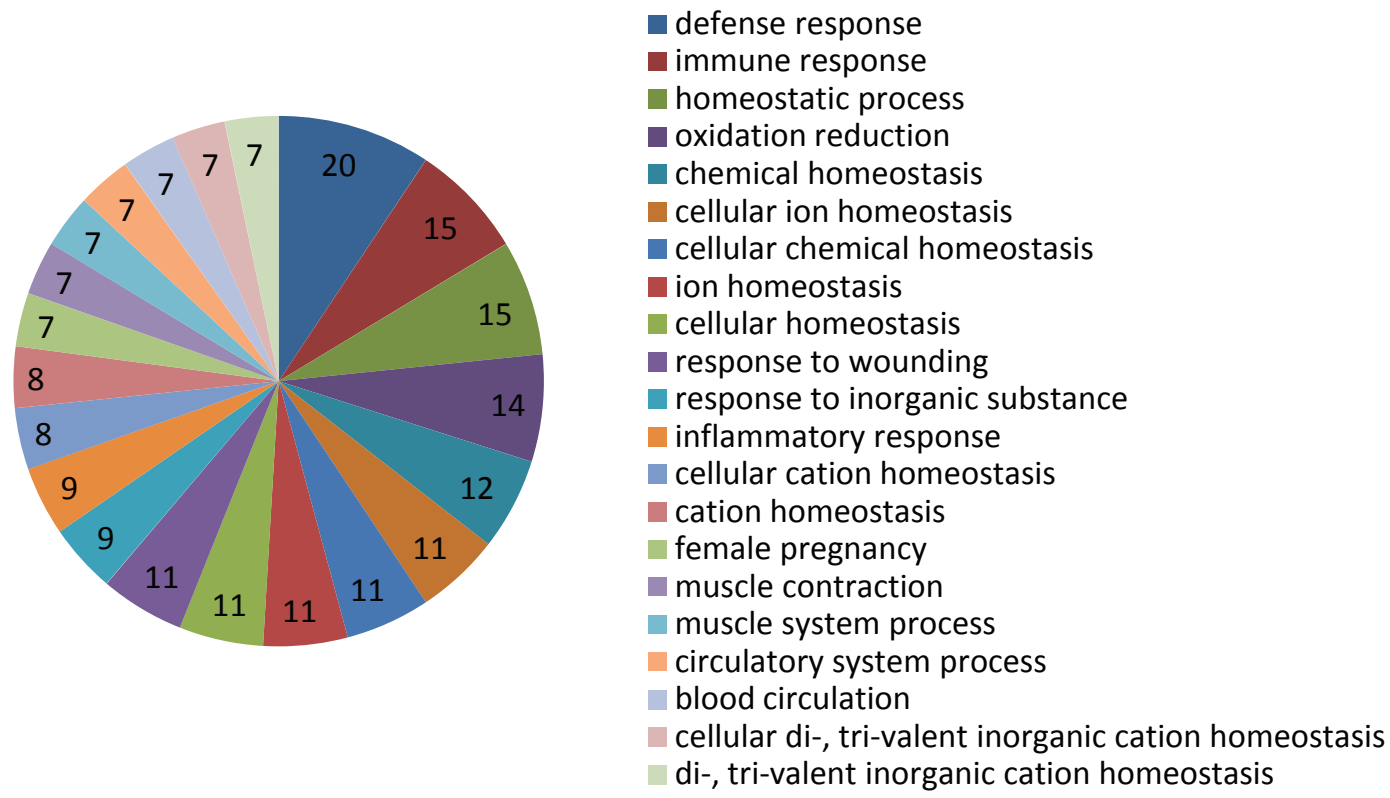

Figure $\mathbf{3}$ GO analysis of the $\mathbf{1 5 4}$ organ-specific genes. The numbers in the pie chart are the number of represented genes in a GO term. 
study, we illustrate the features of HOMER by testing the association between liver-specific genes/proteins and the liver diseases.

We first investigated the liver-specific gene/protein by querying organ by liver (Figure $1 \mathrm{~b}$ and $1 \mathrm{c}$ ). We obtained 317 liver-specific genes (195 in dbEST, 193 in TisGeD [11], 2 in HPA). These proteins include major plasma proteins such as ALB, factors in hemostasis and fibrinolysis such as PLG, carrier proteins such as SERPINA6, hormones such as IGF2, prohormones such as AGT and SERPINA7, and apolipoproteins such as APOA1. This number of proteins may suggest that the proteins which are produced in the liver and secreted into the blood have a high percentage of secretion in liver-specific genes.

We further investigated the disease status of the 317 liver-specific genes by querying for diseases of the liver (Figure 1d). We found that 248 (77.3\%) out of the 317 liver-specific genes are associated with liver-related diseases. For example, those liver-related diseases include MESH:D006394 (Hemangiosarcoma), MESH:D006501 (Hepatic Encephalopathy), MESH:D006527 (Hepatolenticular Degeneration), MESH:D008103 (Liver Cirrhosis), MESH:D008107 (Liver Diseases), and MESH:D010382 (Peliosis Hepatis). 245 (99\%) out of the 248 are validated as directly related to the liver by Disease Ontology [15]. We, therefore, concluded that liver-specific genes/proteins identified by HOMER are more likely to be associated with diseases related to the liver. In the future, we will test whether this conclusion can be applied to the other organs.

Case study 2: organ-specific gene set enrichment analysis We downloaded microarray data from GEO [20] for six organs: lung, ovary, prostate, bladder, pancreas, and kidney (Table 3 ). We then created a phenotype table of normal and disease states for each reference series. Next, we built 52 organ-specific gene sets (for example, a lung-specific gene set consists of 115 organ-specific genes, an ovary-specific gene set 96 organ-specific genes, a prostate-specific gene set 144 organ-specific genes, a bladder-specific gene set 71 organ-specific genes, a pancreas-specific gene set 161 organ-specific genes, and a kidney-specific gene set 191 organ-specific genes) and 10 random non-specific gene sets using the organ-specific gene set enrichment analysis method explained in the method section.

After preparing the three data files - expression datasets, phenotype labels, and gene sets- we loaded them into R-GSEA, set the analysis parameters, and ran the analysis for every reference series. For example, the GSEA results for GSE16538 are shown in Figure 4. The genome-wide gene expression profiles in GSE16538 were compared in tissues derived from subjects with
Table 3 Statistics of GEO microarray data for GSEA

\begin{tabular}{|c|c|c|c|}
\hline Organ & Disease & \#Samples & $\begin{array}{l}\text { Reference } \\
\text { series }\end{array}$ \\
\hline Lung & Lung-sarcoidosis & 12 & GSE16538 \\
\hline Lung & adenocarcinoma(Lung Tumor) & 107 & GSE10072 \\
\hline Lung & Cystic Fibrosis & 20 & GSE2395 \\
\hline Lung & Squamous Lung Cancer & 10 & GSE3268 \\
\hline Lung & Malignant pleural mesothelioma & 54 & GSE2549 \\
\hline Lung & Lung-Cancer & 192 & GSE4115 \\
\hline Prostate & prostate cancer & 104 & GSE6099 \\
\hline Prostate & metastatic prostate tumor & 6 & GSE7930 \\
\hline Prostate & metastatic prostate tumor & 164 & GSE6919 \\
\hline Prostate & prostate tumors & 30 & GSE3868 \\
\hline Ovary & ovarian cancer & 24 & GSE14407 \\
\hline Ovary & Serous Carcinoma & 37 & GSE10971 \\
\hline Ovary & polycystic ovary syndrome & 15 & GSE5090 \\
\hline Ovary & Ovarian Endometriosis & 20 & GSE7305 \\
\hline Bladder & carcinomas & 60 & GSE3167 \\
\hline Bladder & Urothelial carcinoma & 17 & GSE24152 \\
\hline Pancreas & soft tissue sarcoma & 39 & GSE2719 \\
\hline Pancreas & $\begin{array}{l}\text { multistep pancreatic } \\
\text { carcinogenesis }\end{array}$ & 22 & GSE19650 \\
\hline pancreas & $\begin{array}{l}\text { Pancreatic Ductal } \\
\text { Adenocarcinoma }\end{array}$ & 78 & GSE15471 \\
\hline pancreas & Clinic Pancreatic Tumor & 52 & GSE16515 \\
\hline Kidney & renal cell carcinoma & 20 & GSE6344 \\
\hline Kidney & hyperaldosteronism & 15 & GSE8514 \\
\hline Kidney & preeclampsia & 6 & GSE6573 \\
\hline Kidney & metastatic prostate tumors & 164 & GSE6919 \\
\hline
\end{tabular}

active pulmonary sarcoidosis $(\mathrm{n}=6)$ and those with normal lung anatomy $(n=6)$. Its original purpose was to test the hypothesis that tissue genome-wide gene expression analysis, coupled with gene network analyses of differentially expressed genes, would provide novel insights into the pathogenesis of pulmonary sarcoidosis [21].

For the lung-specific gene set, five key statistics for the gene set enrichment analysis were reported, Enrichment Score (ES) (0.604), Normalized Enrichment Score (NES) (1.54), familywise-error rate (FWER)(0.287), False Discovery Rate (FDR)(0.425), and Nominal P Value(0.0291). The normalized enrichment score (NES) is the primary statistic for examining gene set enrichment results [22]. By normalizing the enrichment score, GSEA accounts for differences in gene set size and in correlations between gene sets and the expression dataset; therefore, we used the normalized enrichment scores (NES) to compare analysis results across organ-specific gene sets and non-organ-specific gene sets.

Figure 5 displays the normalized enrichment score for all 52 organ-specific gene sets and 10 random nonorgan-specific gene sets over the six organs: lung, ovary, prostate, bladder, pancreas, and kidney. We can see that in the bladder, kidney, lung, ovary and pancreas, the 


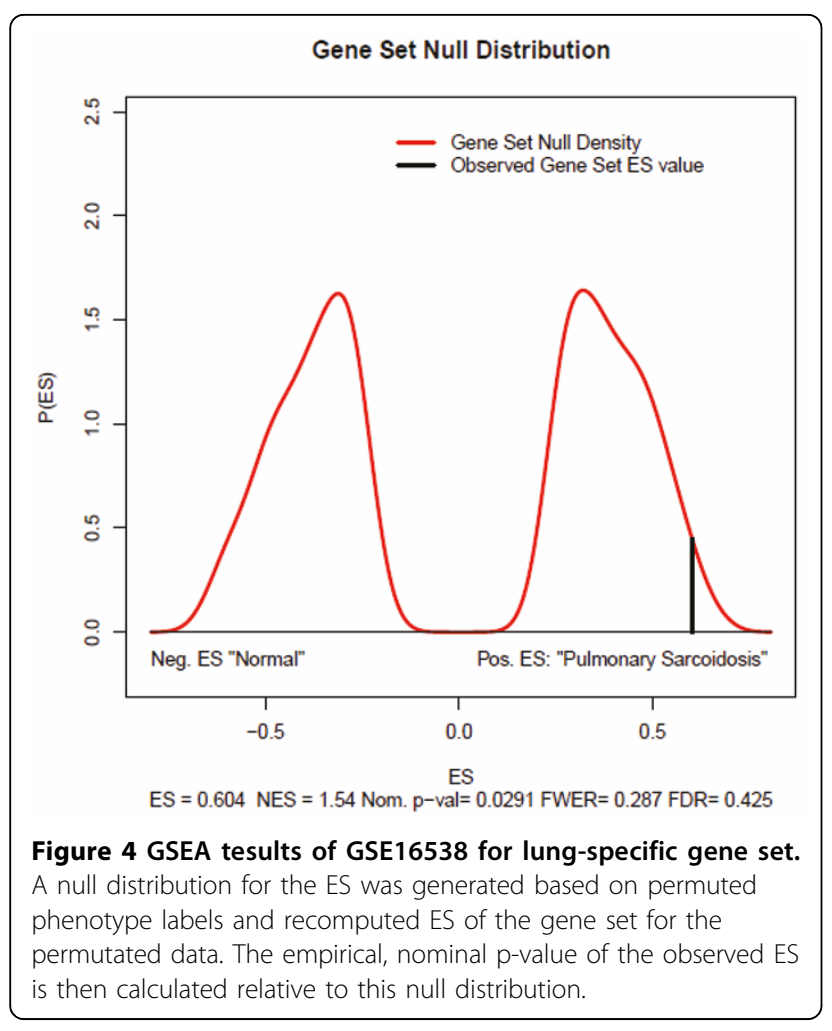

medians of the normalized enrichment scores for organspecific gene sets are above those of the random nonspecific gene sets. This might suggest that organ-specific gene sets are more likely to become enriched in disease samples. On the other hand, we didn't see this characteristic in the prostate. In the prostate, the normalized enrichment scores for organ-specific gene sets are very similar to random non-specific gene sets. Validation for more organs is planned in the future to test our hypothesis that organ specificity of a gene/protein correlates with associated diseases.

\section{Conclusion}

We developed HOMER as an integrated database system to query, analyze, and characterize organ-specific genes/ proteins. HOMER integrates many different types of organ-specific molecular information: organ-specific genes/proteins from the dbEST [13], TiSGED [11], and HPA [12] databases; disease gene relationship from the CTD [14] database; and disease organ relationships from the Disease Ontology [15] database. Organ-specific genes/proteins can be searched, displayed, and downloaded from our online user interface. The current HOMER database can help users address a wide range of organ specificity related questions in human disease studies. We also developed a statistical method for organ-specific genes/proteins, which can be extended to other organisms. Last, our database was evaluated by comparison to other known databases and two case studies.

\section{Discussion}

In this paper, we have demonstrated that HOMER can be used to discover and characterize organ-specific genes/proteins from experimental data and to test the hypothesis that there is correlation between the organ

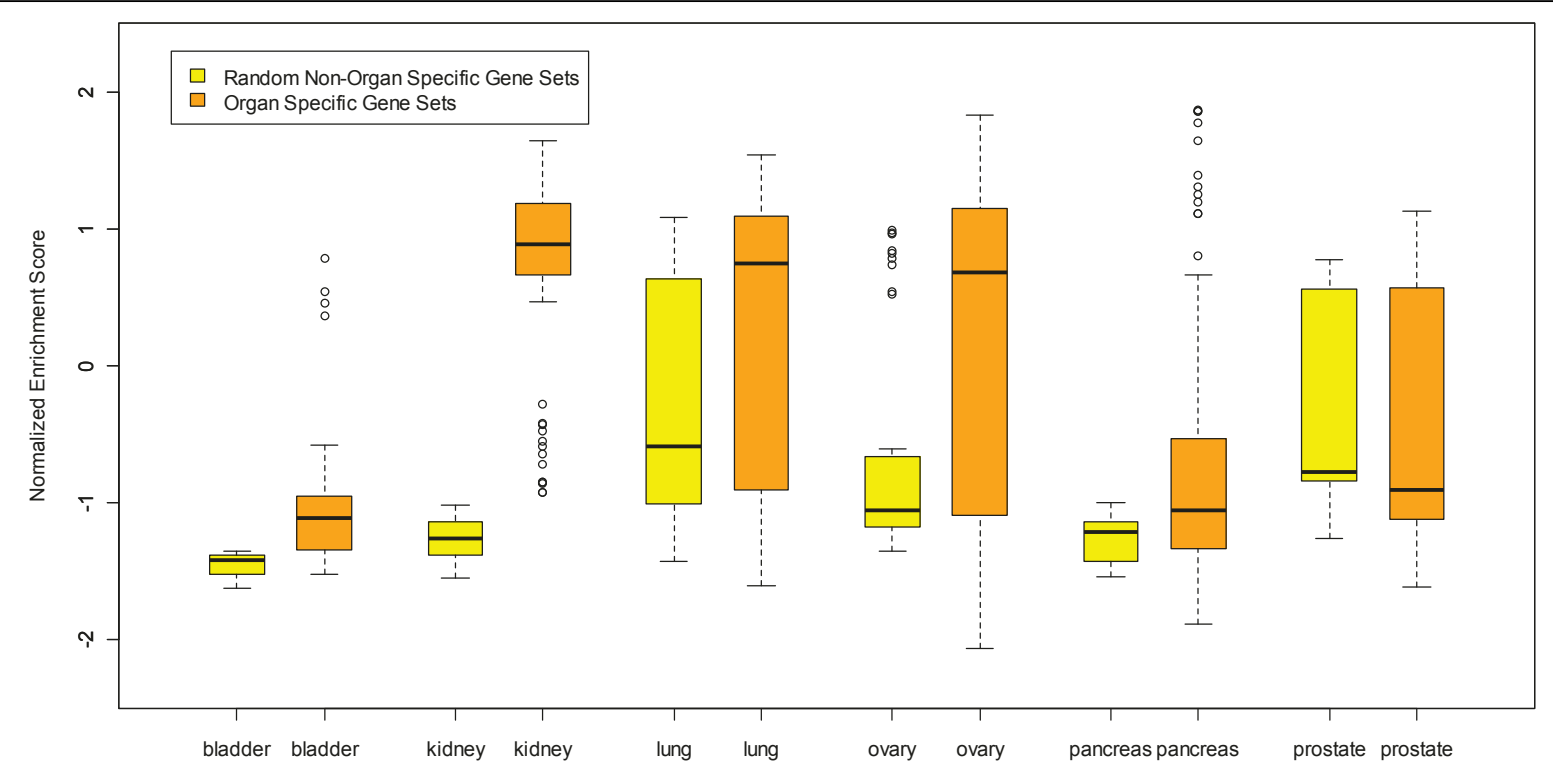

Figure 5 Organ-specific gene sets analysis for lung, ovary, prostate, bladder, pancreas, and kidney. The median normalized enrichment scores of organ-specific gene sets are markedly higher than that of random non organ-specific gene sets, in lung, ovary, bladder, pancreas, and kidney, except for prostate. 
specificity of a gene/protein and the associated diseases. In Case Study 1, we showed that liver-specific genes/ proteins identified by HOMER are more likely to be associated with diseases related to the liver. And in case study 2, we showed that organ-specific gene sets are more likely to become enriched in disease samples in the lung, ovary, bladder, pancreas, and kidney, but not in the prostate. It is obvious that more data and analysis, validation methods and tools, and clinical trials are needed to translate organ-specific biomarkers to clinical applications. With ongoing efforts and as more disease and microarray data are collected, HOMER can become a useful resource to investigate the relationship between organ specificity and organ-related disease.

In biology, an organ is a group of tissues that perform a specific function or group of functions. There are 4 primary tissue types in the human body: epithelial tissue, connective tissue, muscle tissue and nerve tissue. And there are 12 major organ systems in the human body: Circulatory System, Lymphatic System, Digestive System, Endocrine System, Integumentary System, Muscular System, Nervous System, Reproductive System, Respiratory System, Skeletal System, Urinary/Excretory Systems, and Embryonic System. Usually there is a main tissue and sporadic tissues in an organ. For example, the heart is mostly composed of fibroblasts and to some extent of cardiomyoc $[1,24,25]$. Based on the main tissue and the human organ system, we categorized the tissues in dbEST into organs. We found some tissues difficult to categorize in this way, for example, adipose tissue, peritoneum and leiomios (leiomyoma). Since there are too many libraries of those tissues in the dbEST, we decided to categorize them into separate organs with the same name of the tissues.

Adipose tissue and peritoneum don't really belong to any organ system. Adipose tissue is more commonly known as fat, and it helps cushion the skin and provide protection from cold temperatures. All the peritoneum really does is lubricate and drain the abdomen. A leiomyoma (leiomios) is a benign smooth muscle neoplasm that is not premalignant. It can occur in any organ, but the most common forms occur in the uterus, small bowel and the esophagus. In the dbEST, there are 58 libraries which list leiomios, an uncharacterized tissue, as an organ, for example in lib.3508 (http://www.ncbi. nlm.nih.gov/nucest/20967784).

There are also several potential limitations to this study. First, some libraries in dbEST are not labeled clearly for tissues or organs. For example, in lib.50 to lib.70, we cannot get any information about tissues or organs. Second, there are 44 libraries in dbEST which are mixed, such as Lib.589, which pools human melanocyte, fetal heart, and pregnant uterus. We removed these before data analysis. The last possible limitation to the study relates to the relatively small or even absence of microarray sample numbers in some organs. For example, most organs have only 2 to 5 reference series which contain normal and disease states, and there is no microarray data with both normal and disease states for amnion, blood vessel, bone, ear, embryo, gallbladder, ganglia, leiomios, rectum, salivary gland, spinal cord, spleen, thymus, tonsil, trachea, umbilical cord, and ureter. However, with the ongoing development of HOMER and GEO [20], more microarray data will become available and be collected, and more organ-specific genes/proteins may be validated.

\section{Methods}

Pathway analysis, gene ontology categorization, and drug target analysis of organ-specific genes/proteins

We used pathway analysis, gene ontology analysis and drug target analysis to unravel the intricate pathways, functional contexts and targeting drug, and this approach is essential to the understanding of molecular mechanisms of organ-specific genes/proteins.

\section{Function annotation analysis}

DAVID database was used to study biological process in gene ontology. Fisher's exact test is used to test the statistical significance for association between the gene list with expression changes and the function set [26].

\section{Pathway-gene association matrix}

Pathway comparisons were performed using the following databases: Kyoto Encyclopedia of Genes and Genomes (http://www.genome.ad.jp/kegg/) [27] and HPD [28]. The visualization for the pathway-gene association matrix was created by Excel 2010 VBA.

\section{Drug-target analysis}

Drugs and drug targets were retrieved from Drugbank [29]. A light-weight implementation of the Document Object Model interface in Python 2.7.1 [30], xml.dom. minidom, was used to parse the XML format data.

\section{Data source}

We show an overview of the data integration process in Figure 6. Organ-Specific Markers data in HOMER were collected from three different sources, i.e., dbEST [13], TiSGeD [11], and HPA [12].

Raw data of EST reports from dbEST (at 04/19/2011) were downloaded from NCBI. We retrieved the "dbEST ID", "EST name", "GenBank Acc", "Lib Name", "Tissue type", and "Organ" for each EST library under condition that the "Organism" in the EST library is Homo sapiens.

Based on "Lib Name", "Tissue Type", and "Organ", each library was categorized into a corresponding organ category, according to the TissuDB tissue hierarchy [45], 


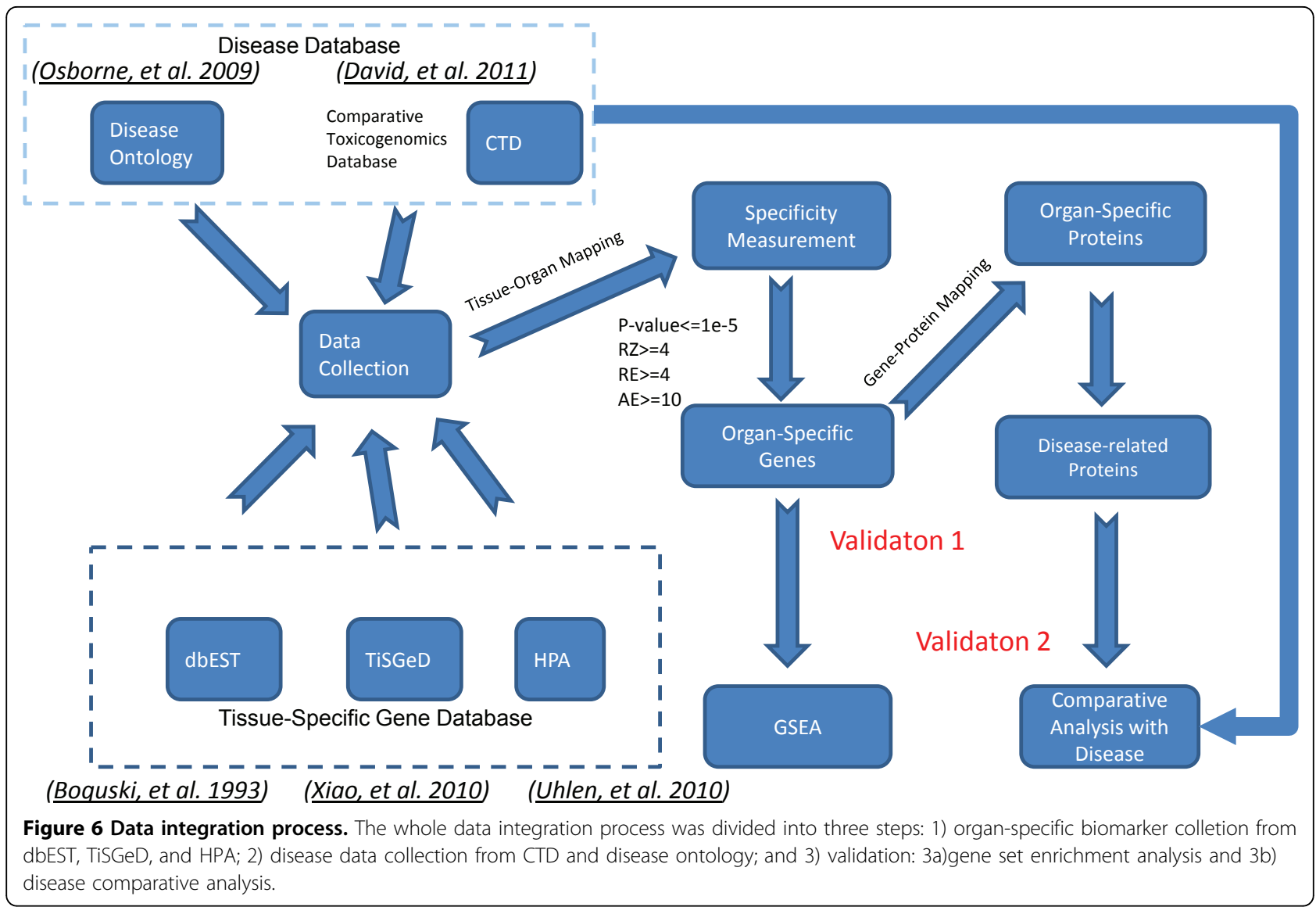

tissue-type terms and their ontological hierarchy in Tissue Ontology [31], and disease of anatomical entity in Disease Ontology [15]. Briefly, our library categorization process is described as follows. For libraries with a definite "Organ", we categorized by "Organ". For libraries with no "Organ", we referred to the descriptions of "Lib Name" and "Tissue Type" and their hierarchy in TissuDB [45], Tissue Ontology [31], or Disease Ontology [15] and manually categorized them into a corresponding organ. Libraries without a definite pathological description were removed. Last, organs with gene number less than 100 and EST number less than 300 were excluded. In all, we downloaded 8,314,483 human ESTs from 8,723 EST libraries, and the screening process described above left us with 8,031 libraries and 6,351,056 ESTs distributed in 111,367 UniGene IDs after converting from "GenBank Acc" and 52 organs (Table 4).

TiSGeD [11] is a database consisting of genes with an associated SPM, which is a measure of its tissue specificity. SPM values range from 0 to 1.0 . Currently there are 2423 human genes from 107 tissues from different organs which have an SPM value above 0.9. A user can also retrieve the data of organ-specific genes, which will be a collection of different tissues constituting that organ. Thus, for the organs of our interest, we include the organ-specific genes having SPM values $>0.9$.

In HPA, we have 4,842 proteins and their expressions across 48 tissues. The expression data were obtained based on analysis of immunohistochemistry-based images in [32] and categorized as negative/weak/moderate/strong. HPA also provides a list of 74 proteins which are found to be expressed in only one cell type.

The Comparative Toxicogenomics Database CTD[14] and Disease Ontology [15] were used to extract the associations between disease and gene/protein and between organ and disease, respectively. We first used perl to convert the Disease Ontology file in OBO format to a relational table in tab-delimited format. Then we used OBO-Edit [33] to open the Disease Ontology file in OBO format and manually parsed the association for each disease and each organ in the disease of anatomical entity (Figure 7). For example, we categorized 25 diseases into the breast (Table 5). After the two steps of parsing, the disease and organ relationships contain 46 organs and 7,850 diseases, 2,600 of which can be mapped into MeSH ID.

The Gene-Disease Relationships were downloaded from CTD [14] website in CSV format and contained 
Table 4 dbEST Statistics for human organs

\begin{tabular}{|c|c|c|c|c|}
\hline \# of ESTs & \# of Libraries & \# of UniGenes & ORGAN & Human Organ System \\
\hline 1343245 & 990 & 41075 & brain & Nervous System \\
\hline 525690 & 293 & 37481 & testis & Reproductive System \\
\hline 453069 & 416 & 33210 & lung & Respiratory System \\
\hline 391891 & 127 & 26930 & liver & Digestive System \\
\hline 259386 & 74 & 26809 & eye & Nervous System \\
\hline 324056 & 258 & 26629 & uterus & Reproductive System \\
\hline 261443 & 202 & 25571 & kidney & Excretory System \\
\hline 347930 & 385 & 23174 & placenta & Embryonic System \\
\hline 280145 & 45 & 22673 & embryo & Embryonic System \\
\hline 202761 & 27 & 22367 & spleen & Immune System \\
\hline 279494 & 986 & 22261 & colon & Digestive System \\
\hline 369626 & 1140 & 21953 & breast & Reproductive System \\
\hline 288058 & 93 & 21901 & skin & Integumentary System \\
\hline 339113 & 350 & 21370 & prostate & Reproductive System \\
\hline 252414 & 48 & 20678 & pancreas & Digestive System \\
\hline 154320 & 72 & 20072 & bone & Skeletal System \\
\hline 148343 & 49 & 19875 & heart & Circulatory System \\
\hline 142041 & 42 & 17744 & muscle & Muscular System \\
\hline 188269 & 354 & 17319 & stomach & Digestive System \\
\hline 132396 & 194 & 16936 & ovary & Reproductive System \\
\hline 172902 & 139 & 16801 & blood & Circulatory System \\
\hline 108962 & 29 & 16781 & lymph node & Lymphatic System \\
\hline 100250 & 35 & 14619 & blood vessel & Circulatory System \\
\hline 92800 & 47 & 13154 & thymus & Immune System \\
\hline 109850 & 329 & 13012 & bone marrow & Immune System \\
\hline 85617 & 58 & 12465 & nerve & Nervous System \\
\hline 92072 & 267 & 11901 & mouth & Digestive System \\
\hline 82442 & 401 & 11618 & thyroid & Endocrine System \\
\hline 48816 & 35 & 10716 & small intestine & Digestive System \\
\hline 105486 & 37 & 9622 & cervix & Reproductive System \\
\hline 41381 & 30 & 9500 & adrenal gland & Endocrine System \\
\hline 55430 & 6 & 9278 & trachea & Respiratory System \\
\hline 56134 & 168 & 8413 & pharynx & Respiratory System \\
\hline 36857 & 66 & 8310 & bladder & Excretory system \\
\hline 56676 & 9 & 7428 & lymph & Lymphatic System \\
\hline 47340 & 273 & 7392 & larynx & Respiratory System \\
\hline 23085 & 4 & 7005 & parathyroid gland & Endocrine System \\
\hline 22976 & 15 & 6229 & pituitary & Endocrine System \\
\hline 21731 & 22 & 5906 & esophagus & Digestive System \\
\hline 16066 & 19 & 5764 & adipose & \\
\hline 19241 & 6 & 5470 & ear & Nervous System \\
\hline 23920 & 10 & 5146 & salivary gland & Digestive System \\
\hline 9612 & 7 & 4296 & ganglia & Nervous System \\
\hline 20474 & 13 & 3719 & tonsil & Immune System \\
\hline 14660 & 17 & 3502 & umbilical cord & Embryonic System \\
\hline 5555 & 2 & 2816 & ureter & Excretory System \\
\hline 12127 & 63 & 2749 & amnion & Embryonic System \\
\hline 6327 & 4 & 2420 & rectum & Digestive System \\
\hline 10640 & 58 & 2218 & leiomios & \\
\hline 2853 & 8 & 1566 & gallbladder & Digestive System \\
\hline 2346 & 3 & 1368 & spinal cord & Nervous System \\
\hline 366 & 7 & 195 & peritoneum & \\
\hline
\end{tabular}




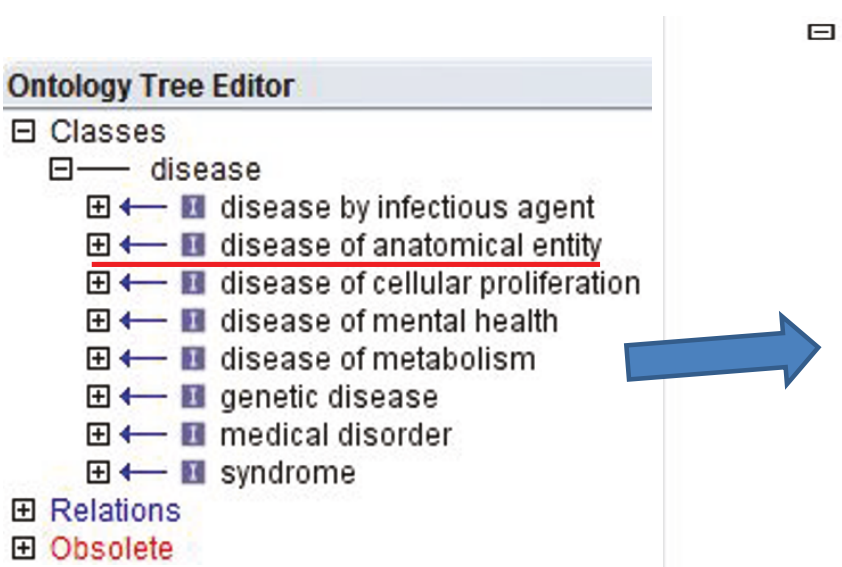

Figure 7 Disease ontology. The class of 'disease of anatomical entity' in the left panel contains 10 subclasses in the right panel. Each subclasses can be further expanded into sub-subclasses.

20,444 genes and 4,290 diseases as of April 7, 2011, 1,096 of which were in common with the diseases in the disease and organ relationships.

The microarray datasets and their latest gene chip annotation files were derived from NCBI GEO [20]. Phenotype tables for each reference series were manually created based on the description of samples we downloaded.

\section{Statistics}

We developed a statistic model based on p-value, zscore and number of ESTs to determine organ specificity of genes.

Given $p$ to be the probability of success in a Bernoulli trial where one EST in gene $i$ falls in organ $j$, the probability of $x$ successes is

$$
P(x)=C_{K}^{x} p^{x}(1-p)^{(K-x)},
$$

Where $K$ is the total number of ESTs in gene $i, M$ is the total number of ESTs in organ $j, N$ is the total number of ESTs in Human, $p=M / N$, and $x$ is the number of ESTs corresponding to gene $i$ in organ $j$.

The p-value for gene $i$ in organ $j$ is the probability of obtaining a test statistic at least as extreme as the one observed, given that the null hypothesis that there is no enrichment between gene $i$ and organ $j$ is true, and calculated according to the formula

$$
\text { Pvalue }=\sum{ }_{x}^{M} P(x)
$$

The absolute expression value (AE, or \#EST) of gene $i$ in organ $j$ is defined as $x$, the number of ESTs corresponding to gene $i$ in organ $j$. The expected expression value $(E E)$ of gene $i$ in organ $j$ is defined as the expected number of ESTs of gene $i$ in organ $j$ under the null hypothesis that the two variables, gene and organ, are independent of each other.

$$
E E=K \cdot \frac{M}{N} .
$$

The relative expression value ( $R E$, or Adjusted \#EST) of a gene $i$ in organ $j$ is defined as $A E / E E$.

The absolute z-score $(A Z)$ shown as follows is used to indicate how many standard deviations an observed absolute expression value in gene $i$ above the mean

$$
A Z=\frac{A E-\overline{A E}}{\sigma_{a e}} .
$$

Similarly, the relative z-score $(R Z)$ is calculated by

$$
R Z=\frac{R E-\overline{R E}}{\sigma_{r e}} .
$$

We define the genes as organ-specific genes if they satisfy the four criteria (i.e. $\mathrm{p}$-value $\leq 10^{-5}, R Z \geq 4, R E \geq$ 
Table 525 primary diseases related to breast

\begin{tabular}{|c|c|c|c|c|c|c|}
\hline ChildID & ChildName & ChildMSHID & ParentID & ParentName & ParentMSHID & Organ \\
\hline & & & DOID:10349 & solitary cyst of breast & & breast \\
\hline DOID:10349 & solitary cyst of breast & & DOID:10350 & breast cyst & $\begin{array}{l}\text { MESH: } \\
\text { D047688 }\end{array}$ & breast \\
\hline \multirow[t]{4}{*}{ DOID:10686 } & lactocele & & DOID:10350 & breast cyst & $\begin{array}{l}\text { MESH: } \\
\text { D047688 }\end{array}$ & breast \\
\hline & & & DOID:10351 & mammary duct ectasia & & breast \\
\hline & & & DOID:10352 & fibroadenosis of breast & & breast \\
\hline & & & DOID:10353 & fibrosclerosis of breast & & breast \\
\hline DOID:3274 & $\begin{array}{l}\text { proliferative type fibrocystic change of } \\
\text { breast }\end{array}$ & & DOID:10354 & breast fibrocystic disease & $\begin{array}{l}\text { MESH: } \\
\text { D005348 }\end{array}$ & breast \\
\hline \multirow[t]{2}{*}{ DOID:5997 } & $\begin{array}{l}\text { non-proliferative fibrocystic change of } \\
\text { the breast }\end{array}$ & & DOID:10354 & breast fibrocystic disease & $\begin{array}{l}\text { MESH: } \\
\text { D005348 }\end{array}$ & breast \\
\hline & & & DOID:10686 & lactocele & & breast \\
\hline DOID:12698 & gynecomastia & $\begin{array}{l}\text { MESH: } \\
\text { D006177 }\end{array}$ & DOID:10688 & hypertrophy of breast & & breast \\
\hline \multirow[t]{5}{*}{ DOID:13520 } & neonatal infective mastitis & & DOID:10690 & mastitis & $\begin{array}{l}\text { MESH: } \\
\text { D008413 }\end{array}$ & breast \\
\hline & & & DOID:10691 & fat necrosis of breast & & breast \\
\hline & & & DOID:11603 & infant gynecomastia & $\begin{array}{l}\text { MESH: } \\
\text { D006177 }\end{array}$ & breast \\
\hline & & & DOID:12698 & gynecomastia & $\begin{array}{l}\text { MESH: } \\
\text { D006177 }\end{array}$ & breast \\
\hline & & & DOID:13520 & neonatal infective mastitis & & breast \\
\hline DOID:3463 & breast disease & $\begin{array}{l}\text { MESH: } \\
\text { D001941 }\end{array}$ & DOID:15 & reproductive system disease & & breast \\
\hline DOID:12698 & gynecomastia & $\begin{array}{l}\text { MESH: } \\
\text { D006177 }\end{array}$ & DOID:1923 & sex differentiation disease & $\begin{array}{l}\text { MESH: } \\
\text { D012734 }\end{array}$ & breast \\
\hline DOID:8310 & sclerosing adenosis of breast & & DOID:3274 & $\begin{array}{l}\text { proliferative type fibrocystic change of } \\
\text { breast }\end{array}$ & & breast \\
\hline DOID:10350 & breast cyst & $\begin{array}{l}\text { MESH: } \\
\text { D047688 }\end{array}$ & DOID:3463 & breast disease & $\begin{array}{l}\text { MESH: } \\
\text { D001941 }\end{array}$ & breast \\
\hline DOID:10688 & hypertrophy of breast & & DOID:3463 & breast disease & $\begin{array}{l}\text { MESH: } \\
\text { D001941 }\end{array}$ & breast \\
\hline DOID:10690 & mastitis & $\begin{array}{l}\text { MESH: } \\
\text { D008413 }\end{array}$ & DOID:3463 & breast disease & $\begin{array}{l}\text { MESH: } \\
\text { D001941 }\end{array}$ & breast \\
\hline DOID:10691 & fat necrosis of breast & & DOID:3463 & breast disease & $\begin{array}{l}\text { MESH: } \\
\text { D001941 }\end{array}$ & breast \\
\hline DOID:11603 & infant gynecomastia & $\begin{array}{l}\text { MESH: } \\
\text { D006177 }\end{array}$ & DOID:3463 & breast disease & $\begin{array}{l}\text { MESH: } \\
\text { D001941 }\end{array}$ & breast \\
\hline DOID:5998 & microglandular adenosis & $\begin{array}{l}\text { MESH: } \\
\text { D005348 }\end{array}$ & DOID:3463 & breast disease & $\begin{array}{l}\text { MESH: } \\
\text { D001941 }\end{array}$ & breast \\
\hline \multirow[t]{2}{*}{ DOID:9504 } & benign mammary dysplasia & & DOID:3463 & breast disease & $\begin{array}{l}\text { MESH: } \\
\text { D001941 }\end{array}$ & breast \\
\hline & & & DOID:5996 & blunt duct adenosis of breast & & breast \\
\hline DOID:10353 & fibrosclerosis of breast & & DOID:5997 & $\begin{array}{l}\text { non-proliferative fibrocystic change of } \\
\text { the breast }\end{array}$ & & breast \\
\hline DOID:5996 & blunt duct adenosis of breast & & DOID:5997 & $\begin{array}{l}\text { non-proliferative fibrocystic change of } \\
\text { the breast }\end{array}$ & & breast \\
\hline DOID:5999 & apocrine adenosis of breast & & DOID:5997 & $\begin{array}{l}\text { non-proliferative fibrocystic change of } \\
\text { the breast }\end{array}$ & & breast \\
\hline DOID:5996 & blunt duct adenosis of breast & & DOID:5998 & microglandular adenosis & $\begin{array}{l}\text { MESH: } \\
\text { D005348 }\end{array}$ & breast \\
\hline DOID:5999 & apocrine adenosis of breast & & DOID:5998 & microglandular adenosis & $\begin{array}{l}\text { MESH: } \\
\text { D005348 }\end{array}$ & breast \\
\hline DOID:7312 & breast adenomyoepithelial adenosis & & DOID:5998 & microglandular adenosis & $\begin{array}{l}\text { MESH: } \\
\text { D005348 }\end{array}$ & breast \\
\hline DOID:8310 & sclerosing adenosis of breast & & DOID:5998 & microglandular adenosis & $\begin{array}{l}\text { MESH: } \\
\text { D005348 }\end{array}$ & breast \\
\hline
\end{tabular}


Table 525 primary diseases related to breast (Continued)

\begin{tabular}{|c|c|c|c|c|c|c|}
\hline \multirow[t]{5}{*}{ DOID:8335 } & microglandular adenosis of breast & & DOID:5998 & microglandular adenosis & $\begin{array}{l}\text { MESH: } \\
\text { D005348 }\end{array}$ & breast \\
\hline & & & DOID:5999 & apocrine adenosis of breast & & breast \\
\hline & & & DOID:7312 & breast adenomyoepithelial adenosis & & breast \\
\hline & & & DOID:8310 & sclerosing adenosis of breast & & breast \\
\hline & & & DOID:8335 & microglandular adenosis of breast & & breast \\
\hline DOID:10349 & solitary cyst of breast & & DOID:9504 & benign mammary dysplasia & & breast \\
\hline DOID:10351 & mammary duct ectasia & & DOID:9504 & benign mammary dysplasia & & breast \\
\hline DOID:10352 & fibroadenosis of breast & & DOID:9504 & benign mammary dysplasia & & breast \\
\hline DOID:10354 & breast fibrocystic disease & $\begin{array}{l}\text { MESH: } \\
\text { D005348 }\end{array}$ & DOID:9504 & benign mammary dysplasia & & breast \\
\hline
\end{tabular}

4, and $A E \geq 10$ ). We determine the parameters based on the following four criteria: 1) $A E$ must be greater than the average absolute expression value of all genes, 2) $R E$ must be greater than the average relative expression value of the genes identified by criteria 1,3 ) at least $95 \%$ of identified organ-specific genes are absolute organspecific gene, and 4) the more organ-specific genes identified, the better.

If a gene is identified as specific to one organ, it is called single-organ-specific gene or absolute organ-specific gene. On the other hand, if a gene is identified as specific to multiple organs, it is called multiple-organspecific gene or relative organ-specific gene.

First, we set $A E \geq 10$ according to experience after rounding to 10 the mean absolute expression value of all the genes in our database, which is 9.56 .

Second, we set $R Z \geq 4$ according to experience after rounding to 4 the mean relative expression value of all the rest genes in our database after filtering with the first criteria, which is 3.85 .

Suppose z-score be from a standard normal distribution, one-tailed p-value of testing the hypothesis that there is no enrichment between gene $i$ and organ $j$ is

$$
P_{\text {norm }}(Z \geq z)
$$

For example, p-value is equal to 2.28E-02, 1.35E-03, 3.17E-05, 2.87E-07, and 9.87E-10, respecitively, when zscore is equal to $2,3,4,5$, and 6 . We round the p-values and obtain five pairs: (p-value $\leq 10^{-2}, R Z \geq 2$ ), (pvalue $\left.\leq 10^{-3}, R Z \geq 3\right)$, (p-value $\left.\leq 10^{-5}, R Z \geq 4\right)$, (pvalue $\leq 10^{-7}, R Z \geq 5$ ), and (p-value $\leq 10^{-10}, R Z \geq 6$ ).

Comparison of the four pairs of parameters is shown in Table 6. The threshold ( $\mathrm{p}$-value $\leq 10^{-10}, R Z \geq 6$ ) is too strict. It filters out about two third of the organspecific genes that are identified by (p-value $\leq 10^{-2}, R Z$ $\geq 2$ ). The thresholds (p-value $\leq 10^{-2}, R Z \geq 2$ ) and (pvalue $\leq 10^{-3}, R Z \geq 3$ ) cannot satisfy the second criteria that requires at least $95 \%$ of identified organ-specific genes are absolute organ-specific gene. Finally, we choose (p-value $\leq 10^{-5}, R Z \geq 4$ ) as thresholds based on the forth criteria because we can identify more organspecific genes with (p-value $\leq 10^{-5}, R Z \geq 4$ ) than with (p-value $\leq 10^{-7}, R Z \geq 5$ ).

\section{Organ-specific gene set enrichment analysis}

Our method for organ-specific gene set enrichment analysis includes three steps: 1 ) collecting microarray data from GEO [20] and creating phenotype tables for each reference series, 2) producing organ-specific gene sets, and 3) running R-GSEA in R programming environment and performing statistical analysis. R-GSEA is the R version of the GSEA program [22]. In order to run it, $R$ release 2.0 or later is required.

We downloaded microarray expression data from GEO [20] for six organs: bladder, kidney, lung, ovary, pancreas, and prostate. The datasets must have data on normal and diseased state with respect to the six organ, based on which we created phenotype tables. We then built an organ-specific gene sets for each of 52 organs. For the comparison of our organ-specific gene set, we built 10 non-specific gene sets by randomly picking up genes which were sufficiently lower ranked to the organ or specific to other organs. We compared the organ-specific gene set(s) with the nonspecific gene sets to determine if the organ-specific gene set was significantly enriched, while other gene sets were not being enriched with regards to a diseased state related to that organ.

Table 6 A comparison of four pairs of P-value and Zscore thresholds

\begin{tabular}{lllll}
\hline & \#OSG & \#R-OSG & \#A-OSG & \%A-OSG \\
\hline p-value $\leq 10^{-2}, R Z \geq 2$ & 9597 & 1913 & 7684 & $80 \%$ \\
p-value $\leq 10^{-3}, R Z \geq 3$ & 8434 & 923 & 7511 & $89 \%$ \\
p-value $\leq 10^{-5}, R Z \geq 4$ & 6569 & 168 & 6401 & $97 \%$ \\
p-value $\leq 10^{-7}, R Z \geq 5$ & 4622 & 0 & 4622 & $100 \%$ \\
p-value $\leq 10^{-10}, R Z \geq 6$ & 2903 & 0 & 2903 & $100 \%$ \\
\hline
\end{tabular}




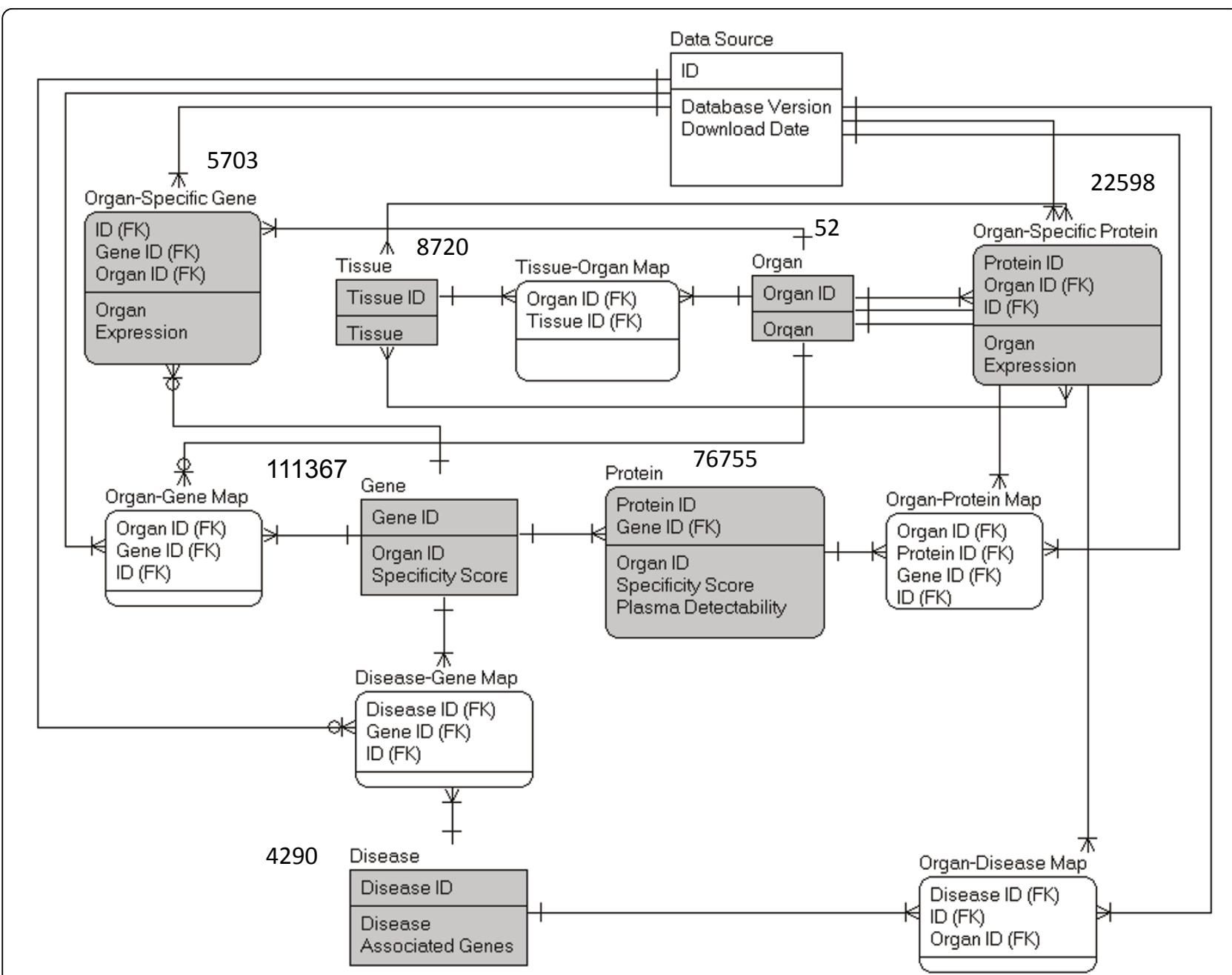

Figure 8 Relational metadata model. The datasets derived by the data generation pipeline are filled in gray.

\section{Online HOMER server design}

The online version of HOMER database is a typical 3tier web application, with an Oracle $10 \mathrm{~g}$ database at the backend database service layer, Apache/PHP server scripts to the middleware application web server layer, and CSS-driven web pages presented on the browser.

The result tables derived from the data generation steps were imported into the Oracle10g database (Figure $8)$. The organ-gene, disease-gene, organ-disease, organprotein, and tissue-organ mapping tables enable users to query the database with different IDs.

\section{Additional material}

Additional File 1: 154 Organ-specific genes. AE: absolute expression RE: relative expression $R Z$ : relative $z$-score

Additional File 2: The pathway-gene association matrix of 154

organ-specific genes. In the organ-gene association matrix, 1 stands for presence of a gene in a pathway and 0 for absence.

Additional File 3: Drug target analysis of 154 organ-specific genes.

\section{Acknowledgements}

This work was supported by a grant from the National Cancer Institute (U24CA126480-01), which is a part of NCl's Clinical Proteomic Technologies Initiative (http://proteomics.cancer.gov). The grant was awarded to Dr. Fred Regnier (PI) and Dr. Jake Chen (Co-PI). We thank for their support the

Indiana Center for Systems Biology and Personalized Medicine. We thank Sumit Makashir and Hrishikesh Lokhande for help with data analysis, data collection, and web development. We especially thank David Michael Grobe from UITS at Indiana University for thoroughly proofreading the manuscript. We also thank three anonymous reviewers for comments that helped us improve this manuscript.

This article has been published as part of BMC Bioinformatics Volume 12 Supplement 10, 2011: Proceedings of the Eighth Annual MCBIOS Conference. Computational Biology and Bioinformatics for a New Decade. The full contents of the supplement are available online at http://www. biomedcentral.com/1471-2105/12?issue=S10.

\section{Author details}

${ }^{1}$ School of Informatics, Indiana University, Indianapolis, IN 46202, USA. ${ }^{2}$ Department of Computer and Information Science, School of Science, Purdue University, Indianapolis, IN 46202, USA. ${ }^{3}$ Indiana Center for Systems Biology and Personalized Medicine, Indianapolis, IN 46202, USA. 


\section{Authors' contributions}

JYC conceived the initial work and designed the method for the database construction. FZ generated the datasets, developed the statistics method, the database backend and the web-based interface, and performed the statistical analyses of the case studies. All authors are involved in the drafting and revisions of the manuscript.

\section{Competing interests}

The authors declare that they have no competing financial interests.

Published: 18 October 2011

\section{References}

1. Klee EW: Data mining for biomarker development: a review of tissue specificity analysis. Clin Lab Med 2008, 28(1):127-143, viii.

2. Kouadjo KE, Nishida Y, Cadrin-Girard JF, Yoshioka M, St-Amand J: Housekeeping and tissue-specific genes in mouse tissues. BMC Genomics 2007, 8:127.

3. Kogenaru S, del Val C, Hotz-Wagenblatt A, Glatting KH: TissueDistributionDBs: a repository of organism-specific tissuedistribution profiles. Theoretical Chemistry Accounts: Theory, Computation, and Modeling (Theoretica Chimica Acta) 2010, 125(3):651-658.

4. Su Al, Wiltshire T, Batalov S, Lapp H, Ching KA, Block D, Zhang J, Soden R, Hayakawa $M$, Kreiman $G$, et al: A gene atlas of the mouse and human protein-encoding transcriptomes. Proc Natl Acad Sci U S A 2004, 101(16):6062-6067.

5. Megy K, Audic S, Claverie JM: Heart-specific genes revealed by expressed sequence tag (EST) sampling. Genome Biol 2002, 3(12):RESEARCH0074.

6. Asmann YW, Kosari F, Wang K, Cheville JC, Vasmatzis G: Identification of differentially expressed genes in normal and malignant prostate by electronic profiling of expressed sequence tags. Cancer Res 2002, 62(11):3308-3314.

7. Laterza OF, Modur VR, Crimmins DL, Olander JV, Landt Y, Lee JM Ladenson JH: Identification of novel brain biomarkers. Clin Chem 2006, 52(9):1713-1721.

8. Wang XS, Zhang Z, Wang HC, Cai JL, Xu QW, Li MQ, Chen YC, Qian XP, Lu TJ, Yu LZ, et al: Rapid identification of UCA1 as a very sensitive and specific unique marker for human bladder carcinoma. Clin Cancer Res 2006, 12(16):4851-4858.

9. Muller PY, Dieterle F: Tissue-specific, non-invasive toxicity biomarkers: translation from preclinical safety assessment to clinical safety monitoring. Expert Opin Drug Metab Toxicol 2009, 5(9):1023-1038.

10. Liu X, Yu X, Zack DJ, Zhu H, Qian J: TiGER: a database for tissue-specific gene expression and regulation. BMC Bioinformatics 2008, 9:271.

11. Xiao SJ, Zhang C, Zou Q, Ji ZL: TiSGeD: a database for tissue-specific genes. Bioinformatics 2010, 26(9):1273-1275.

12. Uhlen M, Oksvold P, Fagerberg L, Lundberg E, Jonasson K, Forsberg M, Zwahlen M, Kampf C, Wester K, Hober S, et al: Towards a knowledgebased Human Protein Atlas. Nat Biotechnol 2010, 28(12):1248-1250.

13. Boguski MS, Tolstoshev CM, Bassett DE Jr.: Gene discovery in dbEST. Science 1994, 265(5181):1993-1994.

14. Davis AP, King BL, Mockus S, Murphy CG, Saraceni-Richards C, Rosenstein M, Wiegers T, Mattingly CJ: The Comparative Toxicogenomics Database: update 2011. Nucleic Acids Res 2011, 39(Database issue):D1067-1072.

15. Osborne JD, Flatow J, Holko M, Lin SM, Kibbe WA, Zhu $\sqcup$, Danila MI, Feng G, Chisholm RL: Annotating the human genome with Disease Ontology. BMC Genomics 2009, 10(Suppl 1):S6.

16. Partap S, Fisher PG: Levetiracetam for seizures in children with brain tumors and other cancers. Pediatr Blood Cancer 2009, 52(2):288-289.

17. Arthur D, Levin ED: Chronic inhibition of alpha4beta2 nicotinic receptors in the ventral hippocampus of rats: impacts on memory and nicotine response. Psychopharmacology (Berl) 2002, 160(2):140-145.

18. Srivareerat M, Tran TT, Salim S, Aleisa AM, Alkadhi KA: Chronic nicotine restores normal Abeta levels and prevents short-term memory and $\mathrm{E}$ LTP impairment in Abeta rat model of Alzheimer's disease. Neurobiol Aging 2011, 32(5):834-844.

19. Olive MF: Pharmacotherapies for alcoholism: the old and the new. CNS Neurol Disord Drug Targets 2010, 9(1):2-4

20. Barrett T, Troup DB, Wilhite SE, Ledoux P, Evangelista C, Kim IF, Tomashevsky M, Marshall KA, Phillippy KH, Sherman PM, et al: NCBI GEO: archive for functional genomics data sets-10 years on. Nucleic Acids Res 2011, 39(Database issue):D1005-1010

21. Crouser ED, Culver DA, Knox KS, Julian MW, Shao G, Abraham S, Liyanarachchi S, Macre JE, Wewers MD, Gavrilin MA, et al: Gene expression profiling identifies MMP-12 and ADAMDEC1 as potential pathogenic mediators of pulmonary sarcoidosis. Am J Respir Crit Care Med 2009, 179(10):929-938

22. Subramanian A, Tamayo P, Mootha VK, Mukherjee S, Ebert BL, Gillette MA, Paulovich A, Pomeroy SL, Golub TR, Lander ES, et al: Gene set enrichment analysis: a knowledge-based approach for interpreting genome-wide expression profiles. Proc Natl Acad Sci U S A 2005, 102(43):15545-15550

23. Banerjee I, Fuseler JW, Price RL, Borg TK, Baudino TA: Determination of cell types and numbers during cardiac development in the neonatal and adult rat and mouse. Am J Physiol Heart Circ Physiol 2007, 293(3): H1883-1891.

24. Nag AC: Study of non-muscle cells of the adult mammalian heart: a fine structural analysis and distribution. Cytobios 1980, 28(109):41-61.

25. Rubart M, Field LJ: Cardiac regeneration: repopulating the heart. Annu Rev Physiol 2006, 68:29-49.

26. Mehta CR, Patel NR, Tsiatis AA: Exact significance testing to establish treatment equivalence with ordered categorical data. Biometrics 1984, 40(3):819-825.

27. Kanehisa M, Araki M, Goto S, Hattori M, Hirakawa M, Itoh M, Katayama T, Kawashima S, Okuda S, Tokimatsu T, et al: KEGG for linking genomes to life and the environment. Nucleic Acids Res 2008, 36(Database issue): D480-484

28. Chowbina SR, Wu X, Zhang F, Li PM, Pandey R, Kasamsetty HN, Chen JY: HPD: an online integrated human pathway database enabling systems biology studies. BMC Bioinformatics 2009, 10(Suppl 11):S5.

29. Knox C, Law V, Jewison T, Liu P, Ly S, Frolkis A, Pon A, Banco K, Mak C, Neveu $V$, et al: DrugBank 3.0: a comprehensive resource for 'omics' research on drugs. Nucleic Acids Res 2011, 39(Database issue):D1035-1041.

30. Myers CR, Sethna JP: Python for Education: Computational Methods for Nonlinear Systems. Computing in Science and Engg 2007, 9(3):75-79.

31. Smith B, Ashburner M, Rosse C, Bard J, Bug W, Ceusters W, Goldberg LJ, Eilbeck K, Ireland A, Mungall CJ, et al: The OBO Foundry: coordinated evolution of ontologies to support biomedical data integration. Nat Biotechnol 2007, 25(11):1251-1255.

32. Ponten F, Gry M, Fagerberg L, Lundberg E, Asplund A, Berglund L, Oksvold P, Bjorling E, Hober S, Kampf C, et al: A global view of protein expression in human cells, tissues, and organs. Mol Syst Biol 2009, 5:337.

33. Day-Richter J, Harris MA, Haendel M, Lewis S: OBO-Edit-an ontology editor for biologists. Bioinformatics 2007, 23(16):2198-2200.

\section{doi:10.1186/1471-2105-12-S10-S4}

Cite this article as: Zhang and Chen: HOMER: a human organ-specific molecular electronic repository. BMC Bioinformatics 2011 12(Suppl 10):S4.

\section{Submit your next manuscript to BioMed Central and take full advantage of:}

- Convenient online submission

- Thorough peer review

- No space constraints or color figure charges

- Immediate publication on acceptance

- Inclusion in PubMed, CAS, Scopus and Google Scholar

- Research which is freely available for redistribution 